\title{
APLICAÇÃO DA METODOLOGIA PDCA E FERRAMENTAS DE GESTÃO DA QUALIDADE PARA REDUÇÃO DE FALHAS E MELHORIA CONTÍNUA: UM ESTUDO DE CASO EM UMA INDÚSTRIA DE EMBALAGENS FLEXÍVEIS
}

\author{
Ana Caroline Lins de Oliveira (UNIFAVIP) carollynelins22@gmail.com \\ Giseli Cezina Silva (UNIFAVIP) giselicezina@gmail.com
}

\section{Resumo}

Ter uma gestão de qualidade dentro das empresas deixou de ser um diferencial e passou a ser uma ferramenta indispensável para as empresas que almejam participar do mercado de forma competitiva, minimizando seus erros e maximizando seus lucros. A empresa em questão é uma indústria de embalagens flexíveis que vem apresentando um grande volume de aparas decorrente das falhas na qualidade de impressão. Através da gestão de qualidade, a empresa busca reduzir ou eliminar as falhas em seu processo produtivo. $\mathrm{O}$ estudo em questão aponta a necessidade do uso da metodologia PDCA juntamente com ferramentas da gestão da qualidade como diferencial na identificação e resolução de problemas em seus processos de forma satisfatória e necessária para a melhoria contínua dentro da empresa. Ao final deste trabalho será possível validar a eficácia do uso da metodologia PDCA com as ferramentas de qualidade para a resolução do problema e como suporte na melhoria contínua dos processos produtivo.

Palavras-chave: Melhoria contínua. Gestão da qualidade. Impressão flexográfica. PDCA.

\section{Introdução}

A flexografia possui diversas variáveis que impactam diretamente nos resultados da impressão. A chapa, a tinta, o anilox, a máquina, o substrato e a própria mão de obra são as principais. Os outros processos de impressão também possuem variáveis semelhantes, porém na flexografia estes são agravados por causa das características do processo. (SCARPETA, 2007).

O cilindro anilox é visto como a peça principal no sistema de entintagem na impressora, que está diretamente relacionado com a tinta e a sua transferência. $\mathrm{O}$ anilox é o responsável por transferir e dosar a quantidade de tinta para a superfície do clichê. Isso deve ser feito de 
forma uniforme e com muita precisão em toda a extensão do cilindro, para que o clichê tenha toda a sua extensão entintada de modo uniforme e que uma parte não fique mais forte ou fraca em relação às outras partes. (SCARPETA, 2007).

Com o uso do cilindro anilox, o mesmo acaba tendo suas células entupidas ocasionando uma redução do volume de tinta a ser transferido para o clichê. Tintas à base de água tendem a ser mais danosas para o anilox. O mais recomendado é limpá-lo no final do trabalho. (SCARPETA, 2007).

Serviços e produtos com qualidade não é algo simples de se alcançar. Para atingir a qualidade faz-se necessário o desenvolvimento e implantação de sistemas de gestão da qualidade nas organizações para garantia do comprometimento de todos com o objetivo de conquistar a excelência nos produtos e processos da empresa, possibilitando seu aprimoramento contínuo. (OLIVEIRA et al., 2004).

Apesar do custo significativo que uma implementação de sistemas da qualidade demanda, muitas empresas os têm implementado, pois cada vez mais as empresas vêm percebendo que há uma forte correlação entre a qualidade e a lucratividade. A qualidade mais elevada pode conduzir à maior lealdade do cliente e culminando, consequentemente, no seu retorno efetivo à compra do produto e/ou serviço. (OLIVEIRA et al., 2004).

Este trabalho tem como objetivo mostrar a aplicação da metodologia PDCA para encontrar e solucionar as falhas do setor de impressão em uma indústria de embalagens flexíveis e trazer, por meio das ferramentas da gestão da qualidade (Brainstorming, Diagrama de Ishikawa, Folha de verificação, e 5W1H) uma solução para o problema identificado.

\section{Referencial teórico}

\subsection{Melhoria contínua}

A melhoria contínua baseia-se no conceito japonês chamado de Kaizen, que consiste na busca pela melhoria gradual de todos os processos, produtos e serviços, descobrindo diariamente uma forma de fazer com que os processos se tornem mais eficientes, mais econômicos e mais confiáveis. Este conceito envolve o desenvolvimento de uma cultura de aperfeiçoamento constante em todas as atividades da empresa. (PEINADO; GRAEML, 2007). 
As empresas podem constatar que estão conseguindo a melhoria contínua quando conseguem obter maior satisfação do cliente, pois a melhoria contínua geralmente está associada a uma redução na variação, um desvio na forma, condição ou aparência de um produto em relação ao padrão de qualidade ao mesmo. Quanto menos um produto varia em relação ao padrão de qualidade ou quanto mais consistente os produtos de uma empresa atendem a um padrão de qualidade, maior é a qualidade. (WILLIAMS, 2017).

Erroneamente diversas pessoas acreditam que a qualidade lida apenas com a padronização de processos e produtos. A padronização de fato é um dos pilares dessa teoria, contudo outro elemento tão importante quanto ela é a melhoria. (OLIVEIRA, 2014).

\subsection{Gestão da qualidade}

Na gestão estratégica, a qualidade é definição com relação aos concorrentes, não a padrões fixos e internos. Quem determina se um produto é aceitável ou não, são os clientes e não os departamentos da empesa. Assim, a preocupação com as especificações passou a ser secundária e só pode ser tratada após cuidadosa identificação das necessidades dos usuários. Se não fosse desta forma a excelência do controle de processo teria pouca vantagem, pois ficaria facilmente desviada do seu real foco: as necessidades dos clientes. (OLIVEIRA et al., 2004).

É importante destacar a relação entre qualidade e produtividade, pois durante muito tempo se pensou que a busca por maior produtividade levasse fatalmente à qualidade inferior, ou seja, divulgou-se a tradicional luta entre quantidade e qualidade. Entretanto, não é verdade que isso necessariamente de fato aconteça, se um produto/serviço ou atividade é feito de forma correta e com qualidade logo na primeira vez, evita-se refazer o trabalho ou consertálo posteriormente. Refazer ou consertar os processos implica em descartar as horas de máquina e homens que foram usadas na realização de coisas mal feitas. Em suma, gasta-se muito mais tempo para fazer a mesma coisa e, consequentemente, implica em uma produtividade menor. Ao contrário, um trabalho bem-feito logo no início economizará tempo e dinheiro, portanto, aumentará a produtividade e a rentabilidade. (MOREIRA, 2012).

\subsection{Ferramentas de qualidade}

\subsubsection{Brainstorming}


O brainstorming, também conhecido como tempestade de ideias, possui como princípio básico o julgamento adiado, visando a facilitação da produção de soluções originais, seguida de uma análise para escolher aquelas com maior potencial e sentido para o problema em questão. $\mathrm{O}$ fato de não possuir julgamento imediato facilita a imaginação e a quebra de barreiras mentais. Seu principal objetivo é a produção do maior número de ideias possíveis sobre um problema necessariamente real. Caso seja aplicado para um problema complicado, deverá então ser decomposto. Essa técnica é utilizada para identificar possíveis soluções para problemas e oportunidades em potencial para a melhoria da qualidade. (MACHADO, 2012).

A ferramenta brainstorming pode ser combinada com o diagrama de Ishikawa para a identificação das potenciais causas para o efeito estudado. Posteriormente essas causas devem ser reduzidas por meio da eliminação das menos prováveis a partir de análise qualitativa e/ou da utilização de técnicas estatísticas apropriadas. (OLIVEIRA, 2014).

\subsubsection{Diagrama de Ishikawa}

O diagrama de causa-efeito, também são conhecidos como diagramas de "espinha de peixe" e "diagramas Ishikawa", é um método particularmente efetivo que ajuda a pesquisar as raízes de problemas. É feito a partir do levantamento de algumas questões: o quê, onde, como e por que, mas desta vez acrescentando algumas "respostas" possíveis de forma explícita. Eles também podem ser usados para identificar áreas em que são necessários mais dados. Os diagramas de causa-efeito tornaram-se extensivamente usados em programas de melhoramentos. (SLACK; CHAMBERS; JOHNSTON, 2002).

O diagrama de Ishikawa é uma representação gráfica que permite a organização de informações por semelhança a partir de seis eixos principais que são chamados de seis $M$ (método, material, máquinas, meio ambiente, mão de obra e medição), possibilitando a identificação das possíveis causas de determinado problema ou efeito, de forma específica e direcionada. (OLIVEIRA, 2014). A Figura 1 abaixo, mostra um exemplo de aplicação do diagrama de Ishikawa. 
Figura 1 - Exemplo de aplicação do diagrama de Ishikawa

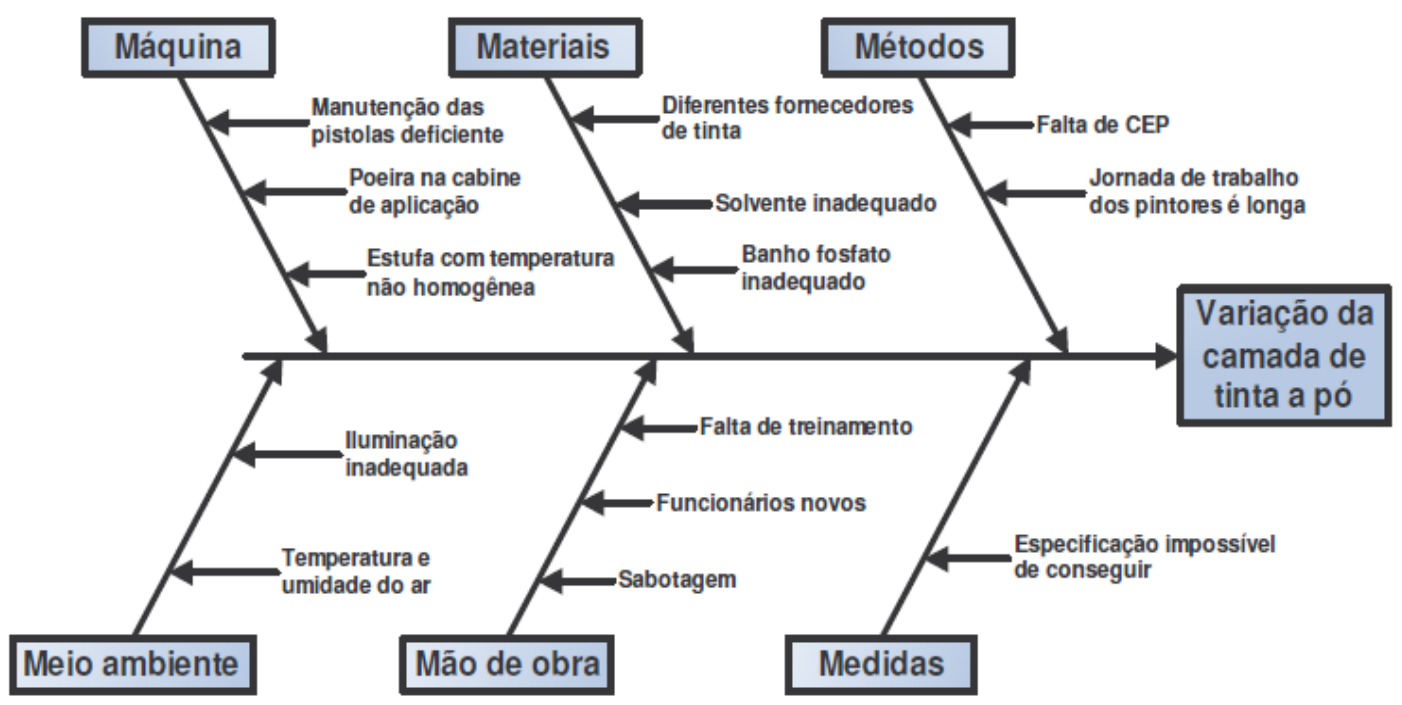

Fonte: Peinado e Graeml (2007)

\subsubsection{Folha de verificação}

A folha de verificação é a ferramenta mais simples e que indica uma maneira de se organizar e apresentar os dados em forma de um quadro ou tabela. (PEINADO; GRAEML, 2007). A Figura 2 mostra um exemplo de folha de verificação.

Figura 2 - Exemplo de folha de verificação

\begin{tabular}{|l|c|c|c|c|c|}
\hline \multirow{2}{*}{ Produto } & \multicolumn{4}{|c|}{ Semana } & \multirow{2}{*}{ Total } \\
\cline { 2 - 5 } & $\mathbf{1}$ & $\mathbf{2}$ & $\mathbf{3}$ & $\mathbf{4}$ & \\
\hline Waffer & 100 & 80 & 50 & 40 & 270 \\
\hline Recheado & 50 & 70 & 80 & 100 & 300 \\
\hline Salgado & 50 & 50 & 55 & 45 & 200 \\
\hline Leite & 80 & 85 & 79 & 82 & 326 \\
\hline Maisena & 47 & 48 & 50 & 49 & 194 \\
\hline
\end{tabular}

Fonte: Peinado e Graeml (2007)

As folhas de verificação podem ser utilizadas para várias finalidades e ocasiões, a escolha depende do objetivo da coleta de dados e deve ser construída após a definição das categorias para a estratificação de dados, que podem ter as mais variadas configurações, como tipos de defeitos, dimensões e características dos itens monitorados (OLIVEIRA, 2014). 


\subsubsection{H1W}

O 5W1H trata-se do checklist usado com a finalidade de garantir que a operação seja realizada sem nenhuma dúvida por parte da chefia ou dos subordinados. As tarefas e seus respectivos responsáveis devem ser claramente definidos para que o projeto de melhoria não sucumba à inércia e falta de determinação (PEINADO; GRAEML, 2007). A Figura 3 e a Tabela 1 abaixo, mostram respectivamente o significado de cada sigla do $5 \mathrm{~W} 1 \mathrm{H}$ e um exemplo de planilha 5W1H:

Figura 3 - Significado do 5W1H

\begin{tabular}{|ll|}
\hline WHAT (O quê?) & Qual a tarefa? O que será feito? Quais são as contramedidas para eliminar \\
& as causas do problema? \\
WHERE (Onde?) & Onde será executada a tarefa? \\
WHY (Por quê?) & Por que esta tarefa é necessária? \\
WHO (Quem?) & Quem vai fazer? Qual departamento? \\
WHEN (Quando?) & Quando será feito? A que horas? Qual o cronograma a ser seguido? \\
HOW (Como?) & Qual o método? De que maneira será feito?
\end{tabular}

Fonte: Peinado e Graeml (2007)

Tabela 1 - Planilha para plano de ação conforme ferramenta 5W1H

\begin{tabular}{|c|c|c|c|c|c|}
\hline \multicolumn{5}{|c}{5 W1H } \\
$\begin{array}{c}\text { What } \\
\text { (o quê?) }\end{array}$ & $\begin{array}{c}\text { Who } \\
\text { (quem?) }\end{array}$ & $\begin{array}{c}\text { When } \\
\text { (quando?) }\end{array}$ & $\begin{array}{c}\text { Where } \\
\text { (onde?) }\end{array}$ & $\begin{array}{c}\text { Why } \\
\text { (por quê?) }\end{array}$ & $\begin{array}{c}\text { How } \\
\text { (como?) }\end{array}$ \\
\hline $\begin{array}{l}\text { Lubrificar } \\
\text { o torno } 2\end{array}$ & $\begin{array}{l}\text { Técnico de } \\
\text { manutenção }\end{array}$ & $\begin{array}{l}\text { Sábado à } \\
\text { tarde }\end{array}$ & Setor X & $\begin{array}{l}\text { Ruído no } \\
\text { mancal }\end{array}$ & $\begin{array}{l}\text { Atendendo às } \\
\text { especificações do } \\
\text { fabricante }\end{array}$ \\
\hline
\end{tabular}

Fonte: Oliveira (2014)

\subsection{Ciclo PDCA}

O PDCA é o modelo referência para o melhoramento contínuo nas empresas devido a sua simplicidade, pois ele proporciona uma linguagem comum a todos no processo de melhoria contínua da qualidade (PEINADO; GRAEML, 2007).

O ciclo PDCA inicia-se com o P (de planejamento), que envolve a coleta de dados para formular um plano de ação para melhorar o desempenho. O próximo estágio é o D (do verbo inglês "do" ou "fazer" em português). Esse é o estágio de implementação durante o qual o plano é testado na operação. Essa etapa pode envolver um mini ciclo PDCA para resolver os 
problemas de implementação. Logo em seguida, vem o C (de checar), no qual a solução nova implementada é avaliada na expectativa de uma melhora de desempenho. E finalmente, pelo menos para este ciclo, vem o estágio A (de agir) (SLACK; CHAMBERS; JOHNSTON, 2002). A Figura 4 abaixo mostra as etapas do ciclo PDCA.

Figura 4 - Etapas do ciclo PDCA

\begin{tabular}{|c|c|c|}
\hline \multirow{4}{*}{$\mathbf{P}$} & 1 & Identificação do problema \\
\hline & 2 & Observação \\
\hline & 3 & Análise para descobrir causas \\
\hline & 4 & Plano de ação \\
\hline & 5 & Ação \\
\hline & 6 & Verificação \\
\hline & $?$ & $\begin{array}{l}\text { Bloqueio foi efetivo? } \\
\text { Não: retorna ao passo } 2 \\
\text { Sim: segue para passo } 7\end{array}$ \\
\hline & 7 & Padronização \\
\hline & 8 & Conclusão \\
\hline
\end{tabular}

Fonte: Peinado e Graeml (2007)

\section{Metodologia}

De acordo com Prodanov e Freitas (2013), a pesquisa científica é classificada quanto ao seu ponto de vista da natureza; do ponto de vista dos seus objetivos; do ponto de vista dos seus procedimentos técnicos e do ponto de vista da forma de abordagem do problema. O estudo em questão é classificado como uma pesquisa aplicada, de natureza exploratória, contendo procedimentos de um estudo de caso que, segundo Yin (2015), é o estudo profundo e exaustivo de forma que permita um amplo e detalhado conhecimento de um ou mais objetos, possuindo uma abordagem qualitativa.

O estudo de caso teve duração de 2 meses e foi realizado em uma indústria de embalagens flexíveis. O ciclo PDCA foi utilizado como metodologia base para a aplicação das ferramentas da qualidade. As ferramentas utilizadas foram: Brainstorming (para encontrar as possíveis causas do problema), Diagrama de Ishikawa (para encontrar a causa raiz), 5W1H (para criar um plano de ação) e a Folha de Verificação (para acompanhar, auxiliar e controlar o processo), para isso foi utilizado papel e caneta, o Microsoft Word, Microsoft 
Visio, e Microsoft Excel, além do estudo do manual técnico da máquina e conversa com operadores e gestores. A metodologia do ciclo PDCA foi aplicada de acordo com as etapas do Quadro 1, abaixo:

Quadro 1 - Aplicação do ciclo PDCA

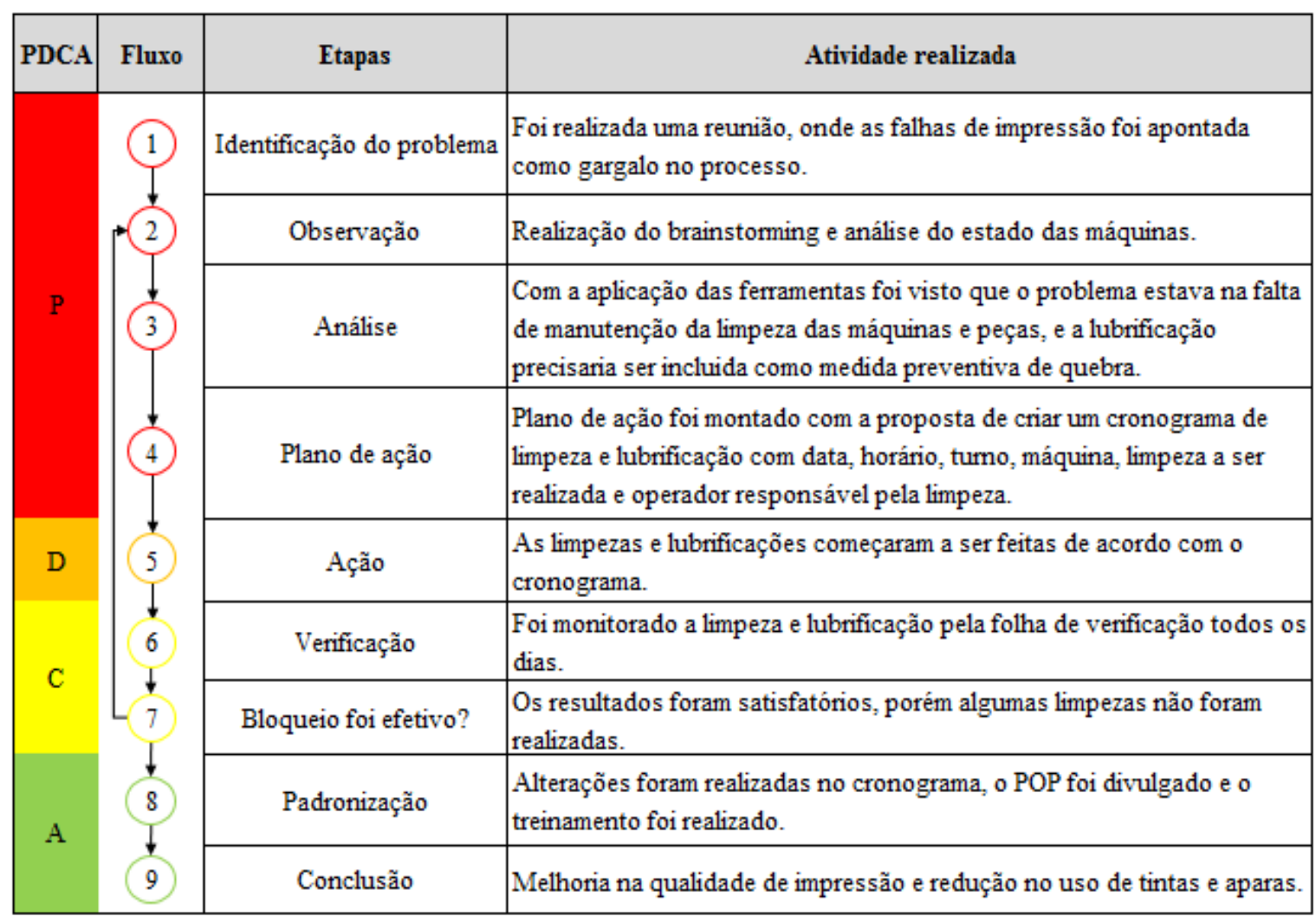

Fonte: Adaptado Campos (1992)

\section{Estudo de caso}

A empresa estudada atua no ramo de embalagens flexíveis oferecendo produtos de qualidade aos segmentos varejistas, atacadistas e de serviços, encontra-se localizada no Agreste pernambucano, e iniciou suas atividades em 2009. Atualmente atende a uma demanda de 15 estados do país, possuindo forte atuação em Pernambuco.

\subsection{PLAN (planejar)}

A identificação das falhas de impressão como gargalo a ser estudado foi considerada através de uma reunião com os gestores, onde apontaram-na como um problema recorrente com impacto negativo na qualidade final do produto, devendo ser, portanto, solucionada o mais rápido possível. Constatou-se também que o percentual de aparas relacionadas a falhas de 
impressão nos últimos 3 meses estavam acima do percentual ideal. Por conseguinte, a meta estipulada para redução desse percentual é de 50\% em relação à média dos últimos 3 meses. Para melhor compreensão e com intuito de identificar as possíveis causas para o gargalo mencionado, aplicou-se a ferramenta brainstorming no setor de impressão com os operários, com o encarregado e as estagiárias de engenharia de produção. O Quadro 2 mostra as possíveis causas apontadas no brainstorming.

Quadro 2 - Aplicação do brainstorming

\begin{tabular}{|c|l|c|c|c|}
\hline \multirow{2}{*}{$\mathbf{N}^{\circ}$} & \multicolumn{1}{|c|}{$\begin{array}{c}\text { Relação de causas que podem estar } \\
\text { provocando o problema }\end{array}$} & \multicolumn{2}{|c|}{ Participantes } \\
\cline { 3 - 5 } & \multicolumn{1}{|c|}{ Estagiárias } & Encarregado & Operários \\
\hline 1 & Falta de padronização no processo de impressão & $\mathrm{X}$ & & \\
\hline 2 & Proporção de tinta e solvente errada & $\mathrm{X}$ & & \\
\hline 3 & Falta de limpeza nas impressoras & & $\mathrm{X}$ & \\
\hline 4 & Depreciação do clichê & & & $\mathrm{X}$ \\
\hline 5 & $\begin{array}{l}\text { Máquinas sem realizar manutenção por um longo } \\
\text { período de tempo }\end{array}$ & & $\mathrm{X}$ & \\
\hline 6 & Tinta de baixa qualidade & & & $\mathrm{X}$ \\
\hline 7 & Temperatura elevada no local de trabalho & & & $\mathrm{X}$ \\
\hline
\end{tabular}

Fonte: As autoras (2020)

Em seguida iniciou-se o acompanhamento de produção observando o estado das máquinas e os procedimentos dos funcionários. Diante de tais observações foi possível descartar alguns dos pontos do brainstorming, tais como:

- Hipótese 2 (proporção de tinta e solvente errada): apesar de ser um item importante com forte influência nos tons das cores e tempo de secagem no processo de impressão, verificou-se que a hipótese em si não tinha uma relação direta com o problema analisado, além disso a medição da viscosidade era feita constantemente pelos operadores;

- Hipótese 6 (tinta de baixa qualidade): foi relatado pelos operadores que a composição das tintas estavam fora do padrão. Um químico industrial foi mandado pelo fornecedor das tintas para averiguação das reclamações, no entanto nada anormal foi constatado.

Para uma análise mais assertiva e com o objetivo de identificar qual a causa raiz do problema, aplicou-se a ferramenta diagrama de Ishikawa conforme a Figura 5 abaixo: 
Figura 5 - Aplicação do diagrama de Ishikawa

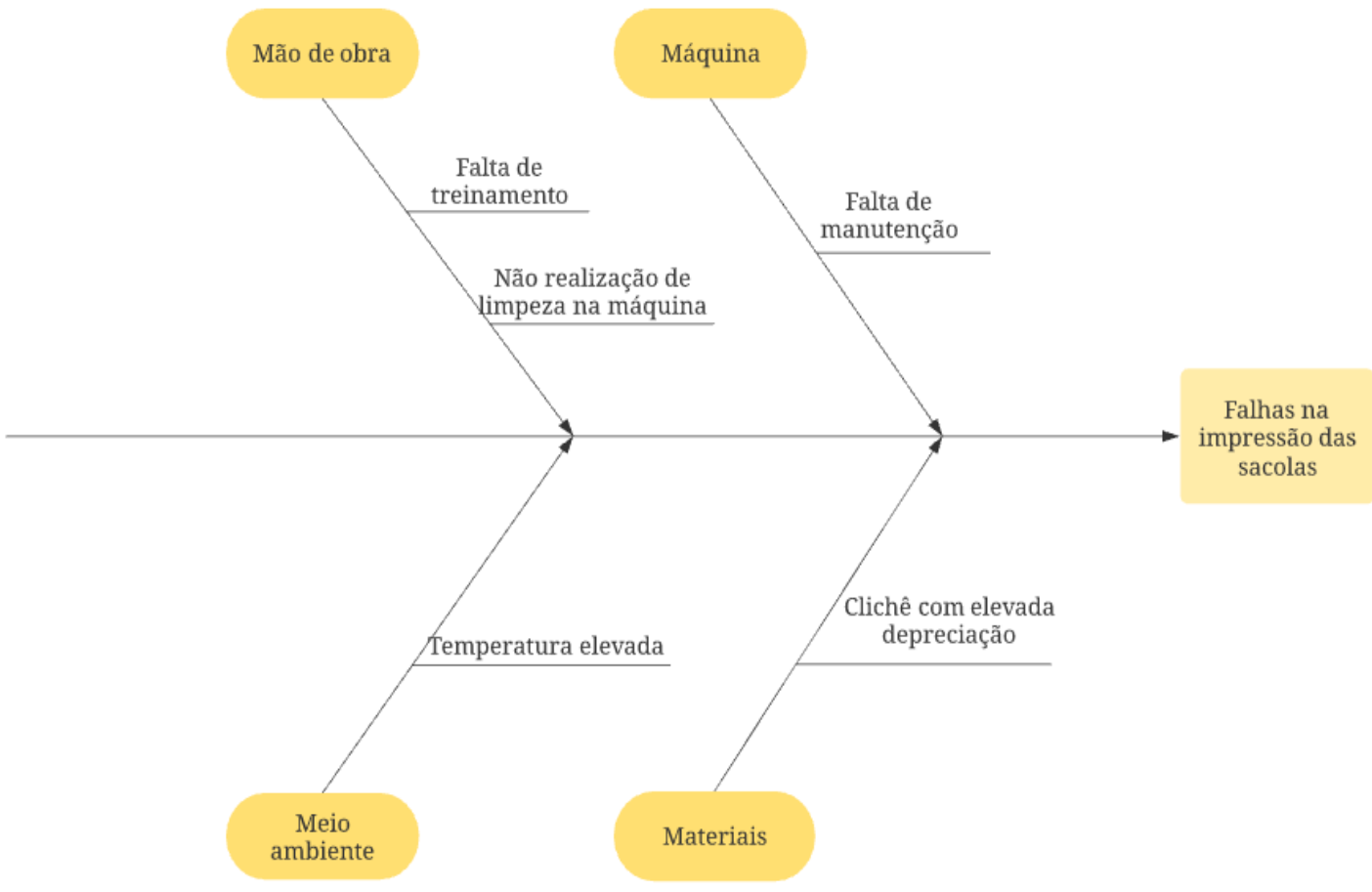

Fonte: As autoras (2020)

A partir do diagrama de causa e efeito, foi possível analisar e averiguar se as causas levantadas têm uma relação direta com o problema apontado e qual o seu impacto nesse problema. Após a análise e o teste de todas as possíveis causas, algumas hipóteses foram descartadas, como:

- Hipótese 1 (falta de treinamento): apesar de ser bastante relevante e recorrente para outros processos, nesse caso em particular, a falta de padronização e treinamento dos operadores, não chegavam a gerar falhas na impressão, pois todos os processos relacionados a impressão estão sendo realizados de forma correta;

- Hipótese 4 (depreciação do clichê): o clichê é parte essencial na impressão, por isso, a empresa tem um rigoroso controle de qualidade, portanto quando constatado um nível de depreciação avançado, é realizado a compra de um novo clichê para substituir o antigo;

- Hipótese 5 (falta de manutenção): foi constatado que as manutenções preventivas estavam sendo feitas periodicamente pelos mecânicos; no entanto as impressoras demandam de lubrificação com alta periodicidade, nas quais algumas não estavam sendo feitas no tempo adequado; 
- Hipótese 7 (temperatura elevada): por ser uma indústria localizada no Agreste com muitos maquinários funcionando ao mesmo tempo, a temperatura no local é elevada, no entanto, encontra-se dentro dos padrões para a atividade em questão.

Por final, uma hipótese apresentou forte relação com o problema: a falta de limpeza interna nas impressoras, mais especificamente no cilindro anilox, ele é responsável pela distribuição uniforme da tinta por todo clichê, e faz parte do sistema de entintagem responsável por todo o caminho que a tinta percorre dentro da impressora, indo desde a bomba de tinta até a impressão no substrato.

A partir da identificação do problema, encontrou-se como solução a realização de um cronograma de limpeza programada contendo também a lubrificação das engrenagens, para otimização do tempo e processo em que a máquina ficará parada. A falta de lubrificação não tem relação direta com o gargalo, mas causa outros problemas como o desgaste prematuro de peças e a parada de máquinas e, portanto, foi acrescentado no cronograma como medida preventiva a quebra. A frequência de lubrificação foi definida em conversa com operários, mecânicos e estudo do manual técnico da máquina. Para solucionar o problema foi realizado o seguinte plano de ação como mostra o Quadro 3.

Quadro 3 - Plano de ação

\begin{tabular}{|c|c|c|c|c|c|}
\hline O quê? & Onde? & Quando? & Quem? & Como? & Por que? \\
\hline $\begin{array}{c}\text { Será elaborado um } \\
\text { cronograma, } \\
\text { contendo as } \\
\text { limprezas } \\
\text { programada e } \\
\text { lubrificação }\end{array}$ & $\begin{array}{c}\text { No setor de } \\
\text { impressão, nas } \\
\text { máquinas } \\
\text { impressoras }\end{array}$ & $\begin{array}{c}\text { O cronograma de } \\
\text { limpeza tem } \\
\text { duração de um } \\
\text { mês, mas é um } \\
\text { processo contínuo } \\
\text { onde todo mês } \\
\text { deve ser atualizado }\end{array}$ & $\begin{array}{c}\text { O impressor e o } \\
\text { auxiliar de } \\
\text { impressão }\end{array}$ & $\begin{array}{c}\text { Será executada } \\
\text { através de } \\
\text { limpezas utilizando } \\
\text { solvente, flanelas e } \\
\text { produto de } \\
\text { limpeza para } \\
\text { anilox }\end{array}$ & $\begin{array}{c}\text { Para melhorar a } \\
\text { qualidade de } \\
\text { impressãando assim } \\
\text { falhas e erros de } \\
\text { impressão }\end{array}$ \\
\hline
\end{tabular}

Fonte: As autoras (2020)

\subsection{DO (fazer)}

Seguindo o plano de ação traçado para atacar as causas raiz do problema, o cronograma foi desenvolvido em dois formatos:

- Um calendário, apenas para visualização de qual dia a limpeza e lubrificação serão realizadas; 
- Um quadro contendo as datas, turnos, máquinas a serem limpas, horário de início, campo para colocar a duração da limpeza e outro campo para assinatura dos responsáveis pela limpeza.

O cronograma foi construído levando em consideração a equipe escalada para o dia e a duração da limpeza. Posteriormente foi exposto em painéis próximos às máquinas impressoras. Em seguida realizou-se uma breve reunião com operários e encarregado de impressão para repassar as atividades que deveriam ser executadas. O cronograma começou a ser executado imediatamente no começo do mês de fevereiro, como planejado e discutido na reunião com os operários. A Figura 6 mostra como foi distribuído às atividades no Cronograma de limpeza, e no Quadro 4 mostra mais detalhadamente as informações a serem seguidas para realização da limpeza.

Figura 6 - Cronograma de limpeza e lubrificação programada

\begin{tabular}{|c|c|c|c|c|c|c|}
\hline DOMINGO & SEGUNDA-FEIRA & TERÇA-FEIRA & QUARTA-FEIRA & QUINTA-FEIRA & SEXTA-FEIRA & SÁBADO \\
\hline 26 & 27 & 28 & 29 & 30 & 31 & 1 \\
\hline 2 & $\begin{array}{l}3 \\
\text { Limpeza do cilindro } \\
\text { anilox: cor } 1,2 \text { e } 3 \\
\text { Lubrificação }\end{array}$ & $\begin{array}{l}4 \\
\text { Limpeza do cilindro } \\
\text { anilox: cor } 4,5 \text { e } 6\end{array}$ & $\begin{array}{l}5 \\
\text { Limpeza do cilindro } \\
\text { anilox: cor } 1 \text { e } 2 \\
\text { Lubrificação }\end{array}$ & $\begin{array}{l}6 \\
\text { Limpeza do cilindro } \\
\text { anilox: } \operatorname{cor} 3 \mathrm{e} 4\end{array}$ & $\begin{array}{l}\quad 7 \\
\text { Limpeza do cilindro } \\
\text { anilox: cor } 1,2 \text { e } 3 \\
\text { Lubrificação }\end{array}$ & $\begin{array}{l}8 \\
\text { Limpeza do cilindro } \\
\text { anilox: cor } 4,5 \text { e } 6\end{array}$ \\
\hline $\begin{array}{l}9 \\
\text { Troca das mangueiras } \\
\text { das bombas de tinta }\end{array}$ & 10 & $\begin{array}{l}11 \\
\text { Limpeza do grupo } \\
\text { impressor: cor } 1,2 \text { e } 3\end{array}$ & $\begin{array}{l}12 \\
\text { Limpeza do grupo } \\
\text { impressor: cor } 4,5 \text { e } 6\end{array}$ & 13 & $\begin{array}{l}14 \\
\text { Limpeza do grupo } \\
\text { impressor: cor } 1,2 \text { e } 3\end{array}$ & $\begin{array}{l}15 \\
\text { Limpeza do grupo } \\
\text { impressor: cor } 4,5 \text { e } 6\end{array}$ \\
\hline $\begin{array}{l}16 \\
\text { Limpeza do grupo } \\
\text { impressor: cor } 1,2,3 \mathrm{e} \\
4\end{array}$ & $\begin{array}{l}17 \\
\text { Limpeza do cilindro } \\
\text { anilox: cor } 1,2 \text { e } 3 \\
\text { Lubrificação }\end{array}$ & $\begin{array}{l}18 \\
\text { Limpeza do cilindro } \\
\text { anilox: cor } 4,5 \text { e } 6\end{array}$ & $\begin{array}{l}19 \\
\text { Limpeza do cilindro } \\
\text { anilox: cor } 1 \text { e } 2 \\
\text { Lubrificação }\end{array}$ & $\begin{array}{l}20 \\
\text { Limpeza do cilindro } \\
\text { anilox: } \operatorname{cor} 3 \mathrm{e} 4\end{array}$ & $\begin{array}{l}21 \\
\text { Limpeza do cilindro } \\
\text { anilox: cor } 1,2 \text { e } 3 \\
\text { Lubrificação }\end{array}$ & $\begin{array}{l}22 \\
\text { Limpeza do cilindro } \\
\text { anilox: cor } 4,5 \text { e } 6\end{array}$ \\
\hline $\begin{array}{l}23 \\
\text { Secagem entre cores: } \\
\text { cor } 1,2 \text { e } 3\end{array}$ & $\begin{array}{l}24 \\
\text { Secagem entre cores: } \\
\text { cor } 4,5 \text { e } 6\end{array}$ & 25 & $\begin{array}{l}26 \\
\text { Secagem entre cores: } \\
\text { cor } 1,2,3 \text { e } 4\end{array}$ & 27 & $\begin{array}{l}28 \\
\text { Secagem entre cores: } \\
\text { cor } 1,2 \text { e } 3\end{array}$ & $\begin{array}{l}29 \\
\text { Secagem entre cores: } \\
\text { cor } 4,5 \text { e } 6\end{array}$ \\
\hline
\end{tabular}

Fonte: As autoras (2020) 
Quadro 4 - Quadro de limpeza e lubrificação programada

\begin{tabular}{|c|c|c|c|c|c|c|}
\hline Data & Turno & Máquina & Dupla & $\begin{array}{l}\text { Horário de } \\
\text { inicio }\end{array}$ & Duração & Assinatura \\
\hline $01 / \mathrm{fev}$ & - & - & & & & \\
\hline $02 /$ fev & - & - & & & & \\
\hline $03 / \mathrm{fev}$ & Noite & Máquina 1 & Dupla do turno escolhido & & & \\
\hline $04 / \mathrm{fev}$ & Noite & Máquina 1 & Dupla do turno escolhido & & & \\
\hline $05 / \mathrm{fev}$ & Manhã & Máquina 2 & Dupla do turno escolhido & & & \\
\hline $06 / \mathrm{fev}$ & Noite & Máquina 2 & Dupla do turno escolhido & & & \\
\hline $07 / \mathrm{fev}$ & Manhã & Máquina 3 & Dupla do turno escolhido & & & \\
\hline $08 / \mathrm{fev}$ & Noite & Máquina 3 & Dupla do turno escolhido & & & \\
\hline $09 / \mathrm{fev}$ & Noite & Máquina 2 e 3 & Dupla do turno escolhido & & & \\
\hline $10 / \mathrm{fev}$ & - & - & & & & \\
\hline $11 / \mathrm{fev}$ & Manhã & Máquina 1 & Dupla do turno escolhido & & & \\
\hline $12 / \mathrm{fev}$ & Noite & Máquina 1 & Dupla do turno escolhido & & & \\
\hline $13 / \mathrm{fev}$ & - & - & & & & \\
\hline $14 / \mathrm{fev}$ & Noite & Máquina 2 & Dupla do turno escolhido & & & \\
\hline $15 / \mathrm{fev}$ & Manhã & Máquina 2 & Dupla do turno escolhido & & & \\
\hline $16 / \mathrm{fev}$ & Noite & Máquina 3 & Dupla do turno escolhido & & & \\
\hline $17 / \mathrm{fev}$ & Manhã & Máquina 1 & Dupla do turno escolhido & & & \\
\hline $18 / \mathrm{fev}$ & Manhã & Máquina 1 & Dupla do turno escolhido & & & \\
\hline $19 / \mathrm{fev}$ & Manhã & Máquina 2 & Dupla do turno escolhido & & & \\
\hline $20 / \mathrm{fev}$ & Manhã & Máquina 2 & Dupla do turno escolhido & & & \\
\hline $21 / \mathrm{fev}$ & Noite & Máquina 3 & Dupla do turno escolhido & & & \\
\hline $22 / \mathrm{fev}$ & Manhã & Máquina 3 & Dupla do turno escolhido & & & \\
\hline $23 / \mathrm{fev}$ & Manhã & Máquina 1 & Dupla do turno escolhido & & & \\
\hline $24 / \mathrm{fev}$ & Noite & Máquina 1 & Dupla do turno escolhido & & & \\
\hline $25 / \mathrm{fev}$ & - & - & & & & \\
\hline $26 / \mathrm{fev}$ & Noite & Máquina 3 & Dupla do turno escolhido & & & \\
\hline $27 / \mathrm{fev}$ & - & - & & & & \\
\hline $28 / \mathrm{fev}$ & Noite & Máquina 2 & Dupla do turno escolhido & & & \\
\hline $29 / \mathrm{fev}$ & Manhã & Máquina 2 & Dupla do turno escolhido & & & \\
\hline
\end{tabular}

Fonte: As autoras (2020)

\subsection{CHECK (verificar)}

Para verificar o andamento das atividades e auxiliar os operadores foi necessário desenvolver uma folha de verificação para acompanhamento e averiguação, como mostra o Quadro 5. Além de servir como forma de controle, também serviu como uma forma de indicador de desempenho, pois através dela acompanhava-se o desenvolvimento das atividades de cada equipe em seus respectivos turnos. Ao longo do mês de execução, foi possível perceber uma certa resistência por parte dos operários em realizar algumas das limpezas que estavam no cronograma, e com o aumento da produção no mês de fevereiro o tempo para realização da limpeza ficou cada vez mais escasso. 
Quadro 5 - Folha de verificação do desempenho de limpeza

\begin{tabular}{|c|c|c|c|c|c|}
\hline \multicolumn{6}{|c|}{ Acompanhamento e controle das limpezas } \\
\hline Data & Turno & Máquina & Limpeza realizada & Responsáveis & Duração \\
\hline & & & & & \\
\hline & & & & & \\
\hline & & & & & \\
\hline & & & & & \\
\hline & & & & & \\
\hline & & & & & \\
\hline & & & & & \\
\hline & & & & & \\
\hline & & & & & \\
\hline
\end{tabular}

Fonte: As autoras (2020)

Apesar do cronograma não ter sido executado por completo devido a alguns imprevistos, o resultado quanto a diminuição da frequência de falhas advindas da impressão foi satisfatória, conseguindo alcançar a meta estipulada pela gerência e tendo uma nítida melhora no setor de impressão. Além da redução nas falhas de impressão foi possível detectar outros ganhos como o cronograma, como por exemplo a redução do uso de tinta devido a manutenção de limpeza do cilindro anilox, que é responsável pela distribuição da tinta para o clichê, pois quando os seus BCM (bilhões de micras cúbicas por polegada quadrada) estão entupidos a transferência de tinta fica comprometida, o que influencia diretamente na força ou na intensidade da cor da impressão no substrato; outro ganho foi a redução de aparas, devido a diminuição de falhas de impressão.

\subsection{ACTION (agir corretivamente)}

Após a verificação da eficácia do cronograma como método de planejamento para realização de limpezas no setor de impressão, e consequentemente da melhoria na qualidade de impressão, algumas medidas precisaram ser realizadas antes de documentar e padronizar todos os processos. Para a correção de algumas ações foi necessária uma reunião com o encarregado de impressão, com os operários e gestores para conscientização dos benefícios que o cronograma estava gerando dentro do setor, e o impacto na qualidade que a limpeza programada teve na correção das falhas. A outra ação corretiva realizada foi a diminuição da quantidade de limpezas contidas no cronograma, essa ação foi necessária para tornar as 
metas de limpeza mais realistas, levando em consideração o aumento na produção e o tempo que cada limpeza leva para ser realizada.

Com as correções efetuadas, foi possível fazer a documentação do procedimento operacional padrão (POP) para a manutenção da melhoria contínua, as limpezas tiveram classificações de limpezas diárias (realizada a cada final de turno) e limpeza programada (realizada de acordo com o cronograma de limpeza). Em seguida foi realizado um treinamento com os operários para a padronização dos processos e disponibilizado ao $\mathrm{RH}$ uma cópia do documento para o treinamento de novos operários.

\section{Conclusão}

A metodologia PDCA juntamente com as ferramentas de qualidade, foram utilizadas neste estudo como fatores determinantes na identificação da falta de limpeza no cilindro anilox, como problema a ser analisado e solucionado. Na sua tratativa obteve-se um resultado satisfatório, pois houve a diminuição da frequência de falhas advindas da impressão, aumentando os padrões de qualidade (pois houve menor variação de cor) e de padronização.

Seguindo o ciclo PDCA, a etapa de planejamento foi essencial para a identificação do problema, levantando possíveis causas que estariam ligadas ao problema, e através delas encontrar a causa raiz, o que possibilitou elaborar um plano de ação que pudesse intervir no problema. A etapa de execução foi baseada na realização do plano de ação, que ajudou a estruturar todo o cronograma de limpeza mensal e alinhar com os operários todas as atividades que deveriam ser realizadas.

A etapa de verificação constituiu na elaboração de uma folha de verificação das atividades, a mesma foi desenvolvida como forma de controle e um importante indicador de desempenho do processo. Devido ao aumento na produção, houveram imprevistos e algumas das limpezas não foram realizadas de acordo com o cronograma. $\mathrm{Na}$ etapa agir algumas medidas corretivas foram necessárias, como uma reunião para a conscientização dos resultados do cronograma, e uma diminuição da quantidade de limpezas que deveriam ser realizadas nos próximos meses, após essas medidas serem tomadas foi possível realizar o POP para a manutenção da melhoria contínua que acontece no ciclo PDCA.

Outros resultados alcançados com o estudo, foram: a redução do consumo de tinta devido ao desentupimento dos BCM do cilindro anilox, quando limpos, conseguem transferir apenas a 
quantidade necessária para a impressão, sendo desnecessário o uso de um grande volume de tinta no sistema de entintagem, e sim apenas a quantidade ideal de pigmento de boa qualidade para que a transferência da tinta seja feita de maneira eficiente; e a redução no volume de aparas, devido a diminuição das ocorrências de falhas na impressão.

Apesar dos acontecimentos inesperados devido ao aumento da produção, a meta estipulada de 50\% para redução nas falhas do setor de impressão foi alcançada e se demonstrou uma solução eficaz para o problema recorrente na empresa.

Para manutenção dos resultados alcançados sugere-se que além do que foi implementado, haja inspeções e orientações por parte do encarregado de impressão durante o seu turno. Além disso para evitar novas ou semelhantes falhas, o setor de impressão deve trabalhar em conjunto com o setor de qualidade de forma a aumentar a frequência de análises das bobinas impressas, e amostras de impressão.

\section{Referências}

ASSOCIAÇÃO BRASILEIRA DE TECNOLOGIA GRÁFICA. ABTG. Manual de impressão flexográfica. 2011.

CAMPOS. V. F. Controle da qualidade total (no estilo Japonês). 7 ed. Belo Horizonte: Fundação Christiano Ottoni, Escola de Engenharia da UFMG, 1992. 229 p.

MACHADO, Simone. Gestão da qualidade. Inhumas: IFG; Santa Maria: Universidade Federal de Santa Maria, 2012. $292 \quad$ p. $\quad 2$ Disponível em 〈http://redeetec.mec.gov.br/images/stories/pdf/eixo_prd_industr/tec_acucar_alcool/161012_gest_qual.pdf>. Acessado em 14 de abril de 2020.

MESQUITA, Teobaldo Campos. Manual de elaboração e apresentação de trabalhos científicos. 3.ed. Fortaleza. Fa7, 2011.

MOREIRA, Daniel Augusto. Administração da produção e operações. 2.ed. rev. e ampl. São Paulo: Cengage Learning, 2012.

OLIVEIRA, Otávio J. Curso básico de gestão da qualidade. 1.ed. São Paulo: Cengage Learning, 2014.

OLIVEIRA, Otávio J. et al. Gestão da qualidade: tópicos avançados. 1.ed. São Paulo: Cengage Learning, 2004.

PEINADO, Jurandir; GRAEML, Alexandre Reis. Administração da produção: operações industriais e de serviços. Curitiba: UnicenP, 2007.

PRODANOV, C. C.; FREITAS. E. C. Metodologia do trabalho científico: Métodos e técnicas da pesquisa e do trabalho acadêmico. $2^{\circ}$ ed. Novo Hamburgo, Rio Grande do Sul. Feevale, 2013.

SCARPETA, Eudes. Flexografia manual prático. 1.ed. São Paulo: Bloco Comunicação Ltda, 2007. 
SLACK, Nigel; STUART, Chambers; JOHNSTON, Robert. Administração da produção. 2. ed. São Paulo: Atlas, 2002.

WILLIAMS, Chuck. ADM: princípios de administração. 2. ed. São Paulo, SP: Cengage editora, 2017.

YIN, Robert K. Estudo de caso: planejamento e métodos. 2.ed. Porto Alegre. Bookman editora, 2015. 